Pesq. Vet. Bras. 37(7):713-724, julho 2017

DOI: $10.1590 / \mathrm{S} 0100-736 \mathrm{X} 2017000700011$

\title{
Ação do extrato etanólico da casca do pequi (Caryocar brasiliense) na cardiotoxicidade crônica induzida por doxorrubicina em ratos ${ }^{1}$
}

\author{
Léa R. Moura ${ }^{2,4}$, Stiwens R.T. Orpinelli", Julia H. Sousa ${ }^{4}$, Mariana B.R. Faleiro ${ }^{4}$, Edemilson \\ C. Conceiçã́o ${ }^{5}$, Denis M. Sugita ${ }^{2}$, Marcelo E. Beletti ${ }^{6}$ e Veridiana M.B.D. Moura ${ }^{4 *}$
}

\begin{abstract}
Moura L.R., Orpinelli S.R.T., Sousa J.H., Faleiro M.B.R., Conceição E.C., Sugita D.M., Beletti M.E. \& Moura V.M.B.D. 2017. [Caryocar brasiliense shell ethanol extract in chronic cardiotoxicity induced by doxorubicin in rats.] Ação do extrato etanólico da casca do pequi (Caryocar brasiliense) na cardiotoxicidade crônica induzida por doxorrubicina em ratos. Pesquisa Veterinária Brasileira 37(7):713-724. Departamento de Medicina Veterinária, Faculdade de Medicina Veterinária e Zootecnia, Universidade Federal de Goiás, Cx. Postal 131, Goiânia, G0 74001-970, Brazil. E-mail: vdmoura@hotmail.com

Doxorubicin (DOX) is a chemotherapic drug used in the treatment of malignancies, but has the cardiotoxicity as collateral effect. The objective of this study was to evaluate the action of pequi shell etanolic extract (Caryocar brasiliense) (PSEE) through morphological evaluation (macroscopic, microscopic and ultramicroscopic), and to evaluate the expression of metalloproteinases (MMP2 and MMP9) and its tissue inhibitors (TIMP1 and TIMP2) in the myocardium of rats with chronic cardiotoxicity by DOX and treated or not with PSEE. The experiment lasted three months and 30 Wistar rats were divided into six groups of five animals. G1 and G2 received $300 \mathrm{mg} / \mathrm{kg}$ and $600 \mathrm{mg} / \mathrm{kg}$ of PSEE, respectively, as pretreatment, by gavage for seven days and continued treatment for 21 days of application of DOX. In G1, G2, G3, G4 and GC, cardiotoxicity was induced with weekly applications of $2 \mathrm{mg} / \mathrm{kg}$ DOX, intraperitoneally, totaling four applications ( $8 \mathrm{mg} / \mathrm{kg})$, and in the Sham group (GS) $1 \mathrm{ml}$ of saline solution was applied. G3 animals received daily $300 \mathrm{mg} /$ $\mathrm{kg}$ of PSEE, and G4, $600 \mathrm{mg} / \mathrm{kg}$, by gavage, for 21 days of application of DOX. The GC and GS received $1 \mathrm{ml}$ of water daily by gavage also. After the completion of the application, the animals were kept for two months, with three months of experiment. Macroscopic evaluation was performed after 90 days, at which time samples were taken for analysis in electron microscopy, histopathology and immunohistochemistry. At necropsy, ascites was observed in animals that received DOX. There was a low mortality rate (3.33\%), being one mouse that developed false road pneumonia. There was no change in weights and measures of the rat hearts. At doses of 300 and $600 \mathrm{mg} / \mathrm{kg}$, the PSEE attenuates myocyte vacuolar degeneration. At a dose of $600 \mathrm{mg} / \mathrm{kg}$, PSEE reduces amount Anitschkow cells. There was no significant result on the immunostaining of MMP, but considering their inhibitors (TIMP) there was a greater immunostaining of TIMP2 in GC, the group that received only DOX. It was concluded that PSEE is effective in minimizing effects of chronic cardiotoxicity induced by DOX in the myocardium of rats, whereas at doses of 300 and $600 \mathrm{mg} /$
\end{abstract}

\footnotetext{
${ }^{1}$ Recebido em 13 de abril de 2016.

Aceito para publicação em 12 de setembro de 2016.

${ }^{2}$ Escola de Medicina, Centro Universitário UniEvangélica, Avenida Universitaria Km 3,5, Cidade Universitaria, Anápolis, GO 75083-515, Brasil. E-mails: lea_vet@hotmail.com,dmsugita@gmail.com

${ }^{3}$ Faculdade Anhanguera de Anápolis, Avenida Universitaria 683, Cidade Universitaria, Anápolis, G0 75083-515. Brasil. E-mail: stiwensqualittas@ hotmail.com

${ }^{4}$ Escola de Veterinária e Zootecnia, Universidade Federal de Goiás
}

(UFG), Rodovia Goiânia-Nova Veneza Km 8, Cx. Postal 131, Goiânia, GO 74001-970, Brasil. E-mails: juliaharger21@hotmail.com, marianafavet@ hotmail.com; *Autor para correspondência: vdmoura@hotmail.com

${ }^{5}$ Faculdade de Farmácia, UFG, Avenida Universitária com a 1aㅡ Avenida s/n, Setor Universitário, Goiânia, GO 75605220, Brasil. E-mail: farmacotecnicaufg@yahoo.com.br

${ }^{6}$ Instituto de Ciências Biomédicas (ICBIM), Universidade Federal de Uberlândia, UFU, Rua Pará 1720, Umuarama, Uberlândia, MG 38440-902, Brasil.E-mail: mebeletti@ufu.br 
$\mathrm{kg}$, PSEE attenuates vacuolar degeneration in myocytes and at the dose of $600 \mathrm{mg} / \mathrm{kg}$ the PSEE reduces the amount of Anitschkow cells and myofibrils fragmentation.

INDEX TERMS: Caryocar brasiliense extract, cardiotoxicity, doxorubicin, metalloproteinases, TIMP, rat.

RESUMO.- A doxorrubicina (DOX) é um quimioterápico utilizado no tratamento de neoplasias malignas, porém possui a cardiotoxicidade como efeito colateral. 0 objetivo deste trabalho foi verificar quanto à ação do extrato etanólico da casca do pequi (Caryocar brasiliense) (EECP) por meio de avaliação morfológica (macroscópica, microscópica e ultramicroscópica), bem como avaliar a expressão de metaloproteinases (MMP2 e MMP9) e seus inibidores teciduais (TIMP1 e TIMP2) no miocárdio de ratos submetidos à cardiotoxicidade crônica pela DOX, tratados ou não com o EECP. O experimento teve duração de três meses e foram utilizados 30 ratos da raça Wistar, distribuídos em seis grupos de cinco animais. G1 e G2 receberam como pré-tratamento $300 \mathrm{mg} / \mathrm{kg}$ e $600 \mathrm{mg} / \mathrm{kg}$ de EECP, respectivamente, por gavagem, durante sete dias e mantiveram o tratamento durante os 21 dias de aplicação da DOX. Em G1, G2, G3, G4 e GC, a cardiotoxicidade foi induzida com aplicações semanais de $2 \mathrm{mg} / \mathrm{kg}$ de DOX, via intraperitoneal, totalizando quatro aplicações $(8 \mathrm{mg} / \mathrm{kg})$ e, nos ratos do grupo Sham (GS), foi aplicado $1 \mathrm{ml}$ de solução fisiológica. Os animais do G3 receberam diariamente $300 \mathrm{mg} /$ $\mathrm{kg}$ e os do G4 $600 \mathrm{mg} / \mathrm{kg}$ de EECP, por gavagem, durante os 21 dias de aplicação da DOX. Os do GC e GS receberam $1 \mathrm{ml}$ de água, diariamente, também por gavagem. Após o término das aplicações, os animais foram mantidos por dois meses, totalizando três meses de experimento. A avaliação macroscópica foi realizada após 90 dias, momento em que foram colhidas amostras para análise em microscopia eletrônica, histopatologia e imunoistoquímica. Ao exame necroscópico foi observada ascite nos animais que receberam DOX. Houve baixo índice de mortalidade $(3,33 \%)$, representado pela morte de um rato que desenvolveu pneumonia por falsa via. Não foi observada alteração no peso e nas medidas do coração dos ratos. Nas doses de 300 e $600 \mathrm{mg} / \mathrm{kg}$, o EECP atenuou a degeneração vacuolar miocítica. Na dose de $600 \mathrm{mg} /$ $\mathrm{kg}$, o EECP reduziu a quantidade de células de Anitschkow e a fragmentação das miofibrilas. Não houve resultado significativo quanto à imunomarcação das MMP e, quanto a seus inibidores (TIMP), houve maior imunomarcação de TIMP2 no GC, grupo que recebeu apenas DOX. Concluiu-se que o extrato etanólico da casca do pequi (EECP) é eficiente em minimizar os efeitos da cardiotoxicidade crônica induzida pela DOX no miocárdio de ratos, considerando que nas doses de 300 e $600 \mathrm{mg} / \mathrm{kg}$ o EECP atenua a degeneração vacuolar miocítica e, na dose de $600 \mathrm{mg} / \mathrm{kg}$, o EECP reduz a quantidade de células de Anitschkow e a fragmentação das miofibrilas.

TERMOS DE INDEXAÇÃO: Caryocar brasiliense, extrato de Pequi, cardiotoxicidade, doxorrubicina, metaloproteinases, TIMP, rat.

\section{INTRODUÇÃO}

A doxorrubicina (DOX), também denominada adriamicina, é um fármaco do grupo das antraciclinas (ANT) que está entre os quimioterápicos utilizados na medicina e na medicina veterinária para o tratamento de diferentes neoplasias malignas, especialmente tumores sólidos, leucemias e linfomas.
Entretanto, possui valor clínico limitado em função de sua cardiotoxicidade (Steinherz et al. 1991, Santos et al. 2009).

Pelos efeitos tóxicos conhecidos, a DOX é utilizada como modelo experimental de cardiomiopatia dilatada em diversas espécies animais (Sousa 2007). Segundo Raj et al. (2014), a cardiotoxicidade da DOX é classificada cronologicamente em aguda, crônica e tardia. A aguda ocorre na primeira semana após a administração do fármaco, a crônica até um ano após o término do tratamento e a tardia se desenvolve anos após a conclusão da terapia anticâncer.

Os efeitos anticancerígenos das ANT ocorrem por meio da inibição da transcrição, síntese e replicação do ácido desoxirribonucleico (DNA), mas também geram radicais livres (RL). A ação desses radicais é definida como estresse oxidativo e designa uma condição na qual ocorre desequilíbrio entre as concentrações de espécies pró e antioxidantes (Pereira 2011). A oxidação é parte fundamental da vida aeróbica e os RL são produzidos naturalmente ou por alguma disfunção biológica. Seu excesso apresenta efeitos prejudiciais, como a peroxidação dos lipídios de membrana e agressão às proteínas, enzimas, carboidratos e DNA (Barreiro et al. 2006).

Estudos comprovam que dietas ricas em antioxidantes naturais contribuem para a redução significativa de doenças crônicas e degenerativas (Paula-Junior et al. 2006). Compostos naturais podem exercer efeitos benéficos na cardiotoxicidade induzida pela DOX, por meio da neutralização de RL (Xin et al. 2011). 0 pequi (Caryocar brasiliense) é um fruto rico em substâncias químicas que possuem atividade antioxidante, bastante difundido na culinária da região centro-oeste, encontrado no cerrado, cerradão e mata calcária, que apresenta também uso medicinal.

0 pequi possui alta concentração de ácido gálico, ácido quínico, polifenois como flavonoide, quercetina e quercetina 3-0-arabinose, tanto no fruto quanto na casca, especialmente quando a extração é etanólica. Tais compostos são antioxidantes naturais que neutralizam RL, podendo reduzir e/ou prevenir o estresse oxidativo (Roesler et al. 2007). 0 pequi possui $209 \mathrm{mg} / 100 \mathrm{~g}$ de compostos fenólicos em todo o fruto, com maior quantidade na casca (Lima 2008). Há descrição de que a capacidade antioxidante do pequi está diretamente relacionada aos compostos fenólicos (Kuskoski et al. 2005).

Quanto à aplicação medicinal do pequi em estudos in vivo, há relato de influência positiva do óleo da polpa do fruto na cicatrização de feridas cutâneas experimentais em ratos. Também foi descrita a ação neuroprotetora do extrato etanólico da casca de pequi em cérebro de ratos submetidos à isquemia e reperfusão (Miguel et al. 2012). Aguilar et al. (2012) avaliaram a ação do óleo do pequi na aterogênese e concluíram que o pequi retarda esse processo nas fases iniciais, possivelmente devido à sua atividade antioxidante. No entanto, o aumento do colesterol no soro induz a maior migração de LDL para a íntima de artérias, acelerando a formação de lesões ateroscleróticas avançadas. Ainda, Oliveira 
(2013) observou o efeito antinociceptivo e anti-inflamatório do óleo da polpa de pequi na artrite induzida por zymosan em ratos e relatou que esse efeito pode estar relacionado à inibição da produção de citocinas pró-inflamatórias.

As metaloproteinases de matriz (MMP) são enzimas responsáveis pela degradação de componentes da matriz extracelular (MEC), que atuam no desenvolvimento e remodelamento normais da MEC ou em processos patológicos (Khasigov et al. 2003). Essas mais de 25 enzimas são classificadas em cinco famílias de diferentes especificidades ao substrato, as colagenases (MMP1, MMP8, MMP13 e MMP18), gelatinases (MMP2 e MMP9), estromelisinas (MMP3, MMP10, MMP11 e MMP26), matrilisina (MMP7) e metaloproteinases de membrana (MMP14, MMP15, MMP16, MMP17, MMP24 e MMP25) (Visse \& Nagase 2003, Page-McCaw et al. 2007). As MMP são secretadas como pró-enzimas inativas e requerem clivagem proteolítica para ativá-las. As MMP degradam macromoléculas da MEC, incluindo colágeno, fibronectina, laminina e proteoglicanas, sendo capazes de degradar todos os componentes da MEC e da membrana basal (Brehmer et al. 2003). São amplamente distribuídas em indivíduos saudáveis, estando envolvidas na embriogênese, em processos de cicatrização de feridas, reabsorção óssea e até mesmo na involução da gândula mamária. Também estão envolvidas em processos patológicos como doenças cardiovasculares, artrites, osteoartrites, afecções periodontais, fibrose hepática, lesões proliferativas da próstata e alterações neoplásicas (Woessner \& Nagase 2000). Leucócitos polimorfonucleares, queratinócitos, monócitos, macrófagos, fibroblastos e células mesenquimais são as principais células responsáveis pela síntese e liberação das MMP. A liberação dessas enzimas é dependente de citocinas, hormônios, fatores de crescimento e até mesmo de fragmentos resultantes da clivagem da MEC por MMP (Nabeshima et al. 2002). Os inibidores de metaloproteinases (TIMP) são proteínas específicas que regulam as atividades dessas enzimas, auxiliando, dessa forma, na manutenção da integridade da MEC (Visse \& Nagase 2003, Parks et al. 2004, Brew et al. 2007, Page-McCaw et al. 2007, Potácová et al. 2007).

O sistema metaloproteinase de matriz (MMPs) é o principal envolvido na degradação da MEC no coração. Um grande reservatório de MMP existe na matriz cardíaca, as quais, após ativação, podem resultar em aumento rápido da atividade proteolítica da MEC. Todos os tipos de células encontradas no miocárdio, quer sob condições basais (miócitos, fibroblastos e células endoteliais) ou em resposta a um estímulo inflamatório (neutrófilos e macrófagos), expressam um ou mais tipos de MMP (Vanhoutte et al. 2006). O colágeno é o principal componente da MEC e, no coração, a principal proteína de sustentação dos cardiomiócitos. Quando a síntese dessa proteína predomina sob a degradação, o resultado é a fibrose. Ao contrário, quando a degradação predomina, a perda do colágeno resulta em disfunção contrátil (Díez 2010).

0 presente estudo teve como objetivo verificar quanto à ação do extrato etanólico da casca do pequi (EECP) (Caryocar brasiliense) por meio de avaliação morfológica (macroscópica, microscópica e ultramicroscópica), bem como identificar e comparar alterações na imonomarcação das proteínas MMP2, MMP9, TIMP1 e TIMP2, no miocárdio de ratos submetidos à cardiotoxicidade crônica pela DOX.

\section{MATERIAL E MÉTODOS}

Toda a conduta experimental seguiu as recomendações referentes à ética em experimentação animal, conforme instruções da Sociedade Brasileira de Ciência em Animais de Laboratório (SBCAL), após submissão à Comissão de Ética no Uso de Animais da Universidade Federal do Goiás (CEUA/UFG 028/12).

A pesquisa foi desenvolvida no Setor de Patologia Animal da Escola de Veterinária e Zootecnia (EVZ) da Universidade Federal de Goiás (UFG), Goiânia, GO, com colaboração do Instituto de Farmácia da UFG, para a obtenção do EECP, e do Serviço de Histologia Veterinária do ICB da Universidade Federal de Uberlândia (UFU), onde foram realizadas as análises em microscopia eletrônica. Foram utilizados 30 ratos (Rattus norvegicus albinus) linhagem Wistar, machos, de três meses de idade e com peso variando entre 281 e 443 gramas, adquiridos para o experimento. Foram utilizados animais da mesma linhagem e sexo para evitar vieses, como interferência hormonal. Os animais foram mantidos na unidade de experimentação animal da EVZ-UFG, sob temperatura de $21^{\circ} \mathrm{C}$, controlada com uso de ar condicionado (Consul, CBV12, Manaus/ AM, Brasil) e verificada por meio de termômetro, e luminosidade (ciclos de 12 horas) controlada com Timer, recebendo dieta padrão (Supra' ração para roedores de laboratório, São Leopoldo/ RS, Brasil) e água ad libitum.

O EECP foi processado a partir das cascas do fruto, de acordo com técnica adaptada de Lima (2008). As cascas foram submetidas a secagem em estufa com ventilação forçada (Solab, 035/5, Piracicaba/SP, Brasil) a $60^{\circ} \mathrm{C}$, por 48 horas, trituradas em moinho analítico (Nogueira máquinas agrícolas, DPM-Júnior, São João da Boa Vista/SP, Brasil) até atingirem baixa granulometria e armazenadas a $-20^{\circ} \mathrm{C}$. Em seguida, foi realizada a percolação em percolador de aço inox (Erli Máquinas, São Paulo/SP, Brasil) a frio, em etanol, ao abrigo da luz e sob agitação. 0 sobrenadante foi filtrado e, após evaporação do solvente, à pressão reduzida, foi obtido o extrato etanólico bruto. Sequencialmente, o extrato foi submetido a testes de qualidade que incluíram avaliação quanto a presença de materiais estranhos, teor de umidade, teor de cinzas totais e granulometria, de acordo com os parâmetros da Farmacopeia Brasileira 5a edição (Brasil 2010). Para avaliar a presença de materiais estranhos, $25 \mathrm{~g}$ do extrato foi espalhado sobre uma bandeja e analisado a olho nu. 0 teor de umidade foi calculado utilizando-se um titulador automático acoplado a um módulo de Karl Fisher (Metrohm, Pensalab, São Paulo/SP, Brasil). Para a determinação do teor de cinzas totais, uma amostra de $3 \mathrm{~g}$ do extrato foi pesada em balança analítica (Marte, XA 110, São Paulo/SP, Brasil) e transferida para um cadinho calcinado em mufla a $450^{\circ} \mathrm{C}$ (EDG equipamentos, Edgecon 1p 3000, São Carlos/SP, Brasil). A amostra foi uniformemente distribuída no cadinho e incinerada a $450^{\circ} \mathrm{C}$, durante $4 \mathrm{~h}$, resfriada em dessecador e novamente pesada. Para a determinação da distribuição granulométrica, $20 \mathrm{~g}$ do extrato foram colocados sobre um jogo de tamises de aço inox (Bertel, Pirassununga/SP, Brasil), de malhas 710, 355, 300, 250, 180,150 e 106 mesh, providos de tampa e recipiente para a coleta do pó. 0 jogo de tamises foi submetido a vibrações em velocidade padronizada nível 5, por 20 minutos. Após esse procedimento, as porções de pó retidas em cada um dos tamises foram pesadas separadamente. 0 percentual dos pós em relação a cada tamis foi calculado de acordo com os parâmetros da Farmacopeia Brasileira 5a edição. Todas essas análises foram realizadas em triplicatas e os resultados expressos em $\%(\mathrm{~m} / \mathrm{m})$ das médias. Finalizado o 
processo, o extrato foi armazenado a $-20^{\circ} \mathrm{C}$ até o momento de fornecimento aos animais.

A aplicação de DOX e solução salina foi intraperitoneal, com cateter número 22, após antissepsia com iodopovidine. Os animais $(n=30)$ foram separados em seis grupos (Grupo Sham - grupo placebo que recebeu apenas solução salina e água [GS], G1, G2, G3, G4 e GC [grupo que recebeu apenas DOX]), sendo cada grupo composto por cinco animais $(n=5)$.

0 experimento teve duração de três meses. Os ratos dos grupos G1 e G2 receberam, como pré-tratamento, 300 e $600 \mathrm{mg} / \mathrm{kg}$ do EECP, respectivamente, por gavagem, durante sete dias e mantiveram o tratamento durante os 21 dias de aplicação da DOX. Em G1, G2, G3, G4 e GC, a cardiotoxicidade foi induzida com aplicações semanais de $2 \mathrm{mg} / \mathrm{kg}$ de DOX (Adriblastina Pfizer, Milão, Itália), por via intraperitoneal, totalizando quatro áplicações $(8 \mathrm{mg} / \mathrm{kg}) \mathrm{e}$, em GS, foi aplicado $1 \mathrm{ml}$ de solução fisiológica (placebo), conforme critérios adaptados de Ferreira et al. (2007). Aos ratos do G3 foram fornecidos diariamente 300 e aos do G4 600mg/kg de EECP, por gavagem, durante os 21 dias de aplicação da DOX. Aos animais dos grupos GC e GS foi fornecido $1 \mathrm{ml}$ de água, diariamente, também por gavagem. Após o término das aplicações, os animais foram mantidos por dois meses, totalizando três meses de experimento. As doses do EECP utilizadas foram baseadas em estudo prévio (Miguel et al. 2012).

A avaliação morfológica foi realizada após 90 dias. Os ratos foram submetidos à eutanásia por sobredose anestésica com isoflurano, em câmara de inalação fechada, administrado através de máscara facial adaptada para a espécie, com oxigênio a $100 \%$ e uso de vaporizador com fluxo de admissão de gases $1 \mathrm{~L} / \mathrm{min}$ (Oxigel, Vaporizador Universal, São Paulo/SP, Brasil). À avaliação necroscópica foi realizada incisão no saco pericárdico e ainda na cavidade torácica foram avaliados espessamentos e aderências, bem como as características e a quantidade de eventuais acúmulos pericárdicos. 0 coração foi separado do sistema respiratório, sendo drenado o conteúdo das câmaras, pesado e, em seguida, aberto, realizando-se incisão longitudinal média, da base ao ápice do coração, expondo as câmaras cardíacas. Foram obtidas medidas referentes ao eixo vertical e horizontal, com base no ponto médio de cada eixo. Para a obtenção dessas medidas foi utilizado paquímetro, conforme critérios adaptados de Pontes et al. (2010). As lesões observadas foram fotografadas e registradas em planilha específica. Fragmentos do coração foram colhidos em formol a $10 \%$ tamponado para histopatologia e imunoistoquímica, e em glutaraldeído para microscopia eletrônica.

Para as análises em microscopia óptica, metade do coração foi fixada durante 48 horas em formol a $10 \%$ tamponado, e posteriormente mantida em álcool $70 \%$ até o momento do processamento, que foi conduzido de acordo com técnicas laboratoriais rotineiras para a inclusão tecidual em parafina. Foram confeccionados cortes histológicos de $4 \mu \mathrm{m}$ em micrótomo (Leica Microsystems, RM2245, Wetzlar, Alemanha), estes distendidos em lâminas histológicas com extremidade fosca e corados por hematoxilina e eosina (HE) para a classificação das alterações histomorfológicas. A análise das lâminas foi realizada em microscópio óptico (Olympus, BX41, Melville, New York, EUA) inicialmente na objetiva de menor aumento $(4 \mathrm{x})$, seguindo-se às objetivas subsequentes $(10 \mathrm{x}$, 40x e 100x). A avaliação histomorfológica foi graduada em escores, seguindo critérios adaptados de Pontes et al. (2010), sendo adotados escores para intensidade da lesão, sendo: 0- (negativa), $1+$ (discreta), $2+$ (moderada) e 3+ (acentuada); e para distribuição das lesões: 0 (ausente), 1+ (focal), 2+ (multifocal) e 3+ (difusa).

Para avaliar possíveis alterações ultramicroscópicas, cinco fragmentos de aproximadamente $1 \mathrm{~mm}^{3}$ de cada coração foram fixados em tubos contendo glutaraldeído a 4\% tamponado em cacodilato de sódio, 0,1M, pH7,2. Após fixação por 48 horas, os espécimes foram lavados com tampão cacodilato $(0,1 \mathrm{M}$, ph7,2) duas vezes, por 10 minutos, e 1 hora em tetróxido de ósmio a 1\% associado a ferrocianeto de potássio a 1,25\%. Em seguida, foram incluídos em resina Epon e cortados em ultramicrótomo para a obtenção de cortes ultrafinos. Os cortes foram contrastados com acetato de uranila e citrato de chumbo, e examinados em microscópio eletrônico (Zeiss, EM-109, Jena, Alemanha). Foram selecionadas para análise duas amostras representativas de cada grupo, previamente avaliadas em microscopia de luz.

Para a avaliação imunoistoquímica, cortes de $3 \mu \mathrm{m}$ foram confeccionados em micrótomo (Leica Microsystems, RM2245, Wetzlar, Alemanha), e distendidos sobre lâminas histológicas Starfrost (Thermo Fisher Scientific, Waltham, EUA). Os cortes foram desparafinizados, hidratados, lavados em água corrente e submetidos à recuperação antigênica a $96^{\circ} \mathrm{C}$, durante 40 minutos, em banho-maria. Subsequentemente, as lâminas foram lavadas com solução tampão TRIS, pH7,4, e realizado o bloqueio da peroxidase endógena com água oxigenada a 3\% em metanol, por 20 minutos. Para o bloqueio de reações inespecíficas, os cortes foram incubados em leite em pó desnatado (Molico Nestlé, Araras, Brasil) a $10 \%$, durante 80 minutos. Em seguida, os cortes foram incubados com anticorpos diluídos (diluidor de anticorpos ADS-125, Spring) a 1:50 para o anticorpo policlonal de coelho anti-MMP2 (Abcam, ab110186), 1:200 para o anticorpo policlonal de coelho anti-MMP9 (DAKO A0150), 1:100 para o anticorpo policlonal de coelho anti-TIMP1 (Spring), e 1:50 para o anticorpo policlonal de coelho anti-TIMP2 (Spring), em câmara úmida, durante duas horas, a $37^{\circ} \mathrm{C}$. Nas lâminas utilizadas como controle negativo, os anticorpos foram substituídos pelo diluidor de anticorpo (ADS-125, Spring). A etapa seguinte referiu-se à incubação dos cortes em sistema de amplificação de sinais com anticorpo secundário Envision Dual Link (DAKO, K4061-1). Para a visualização da reação as lâminas foram submersas em solução de diaminobenzidina (DAB) (Dako K3468-1). Os cortes foram submetidos à contracoloração com hematoxilina de Mayer, lavados, desidratados e diafanizados. As lâminas foram montadas com lamínula e resina sintética, seguindo-se a análise em microscopia para determinação do percentual de área tecidual marcada e intensidade de marcação dos anticorpos empregados. Para isso, foi utilizado microscópio acoplado a câmera digital e sistema de análise de imagens (DM4000, DFC290 e Leica Application Suite, todos da marca Leica Microsystems, Wetzlar, Alemanha).

A intensidade de marcação imunoistoquímica e o percentual de área tecidual marcada para anti-MMP2, anti-MMP9, anti-TIMP1 e anti-TIMP2 no tecido cardíaco de ratos não tratados (GS) e tratados com DOX, com e sem o uso EECP, foi graduada em escores, seguindo critérios de Faleiro et al. (2013), sendo adotados para intensidade de marcação: 0- (negativa, ausência de imunomarcação), 1+ (discreta, imunomarcação fraca), 2+ (imunomarcação moderada) e 3+ (acentuada, imunomarcação forte) (Fig.1). Para o percentual de área tecidual marcada os escores adotados foram: $0=$ negativo, $1=1-25 \%, 2=26-50 \%, 3=51-75 \%$ e $4=76-100 \%$.

0 experimento foi instalado em delineamento inteiramente casualizado, com seis protocolos terapêuticos (GS, G1, G2, G3, G4 e GC) e cinco repetições, sendo que a unidade experimental foi constituída por um animal (rato), totalizando 30 ratos. Para as variáveis quantitativas foram realizadas médias, desvio-padrão, mediana, mínimo e máximo e sua análise inferencial foi realizada utilizando-se análises de variância e o teste de Pearson. Para as variáveis qualitativas, obtidas em escalas de notas, foi realizado o teste de Kruskal-Wallis, teste qui-quadrado, Wilcoxon e Dunn. Para avaliar a correlação entre os anticorpos foram utilizados os testes de Spearman e de U-Mann Whitney. A todos os testes foi adotado o nível de significância de 5\% (p $<0,05)$ e, para realização, utilizado o software estatístico SPSS (IBM Corp. Released 2010. IBM SPSS Statistics for Windows, Version 19.0. Armonk, NY) e R (R CORE development team versão 3.0.0). 


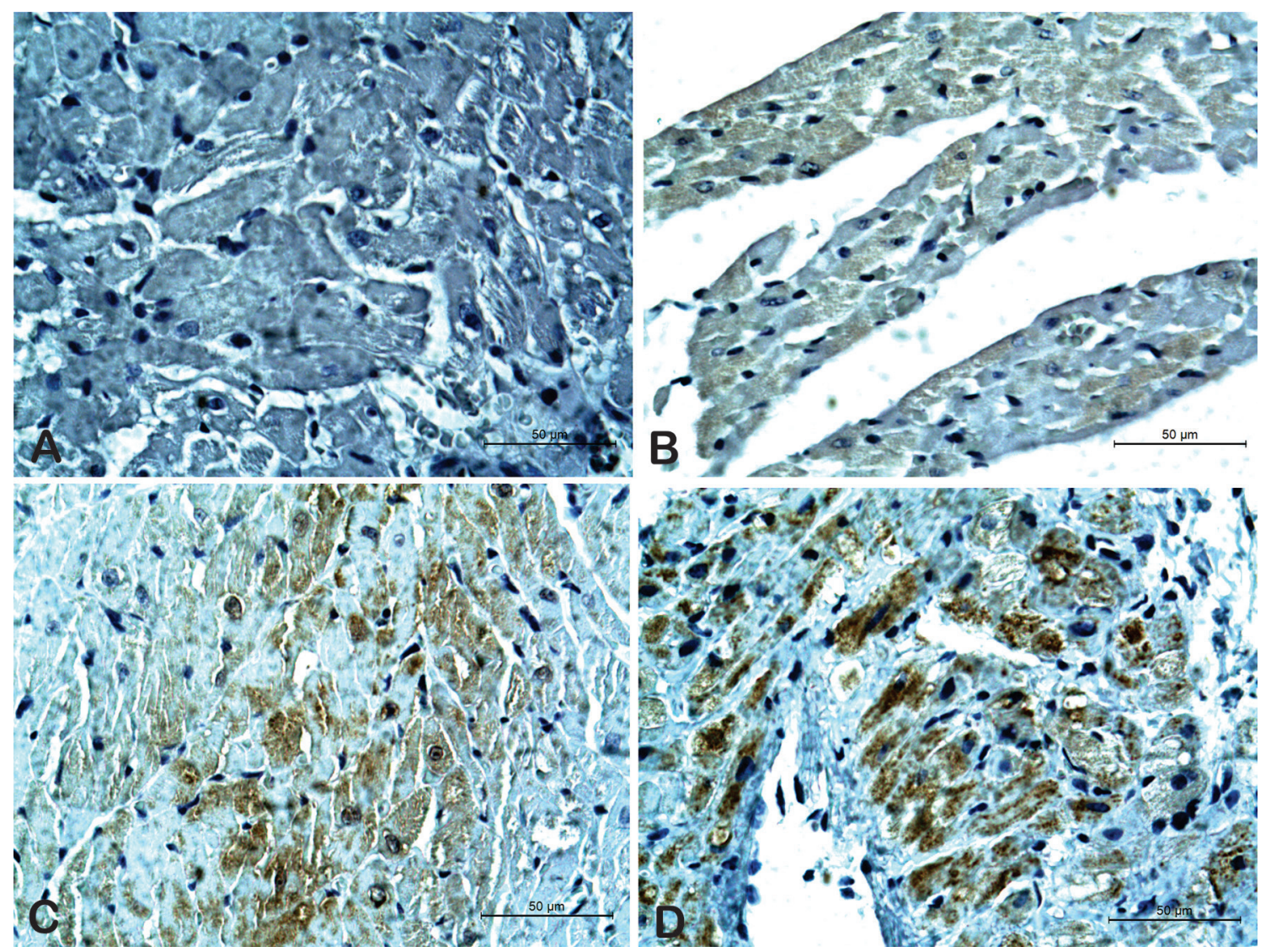

Fig.1. Fotomicrofotografia de escores de intensidade de marcação imunoistoquímica com os anticorpos anti-MMP2, anti-MMP9, anti-TIMP1 e anti-TIMP2 no miocárdio de ratos tratados com DOX, com e sem EECP. (A) Controle negativo (0+); (B) Intensidade discreta (1+) anti-TIMP1; (C) Intensidade moderada (2+) anti-TIMP2; (D) Intensidade acentuada (3+) anti-MMP2. DAB contra corado com Hematoxilina de Mayer.

\section{RESULTADOS}

Nos testes de qualidade do EECP produzido não foram encontrados materiais estranhos. 0 teor de umidade da amostra foi de $9,03 \pm 0,283 \%$. Já o de cinzas totais foi de $5,87 \%$ $\pm 0,06$. Após a tamisação do pó vegetal constatou-se que a totalidade das partículas não passou pelo tamis de malha de $710 \mu \mathrm{m}$, e menos de $40 \%$ passaram pelo tamis de malha de $355 \mu \mathrm{m}$, caracterizando o pó como grosso (Brasil 2010).

A mortalidade constatada no experimento foi de 3,33\%

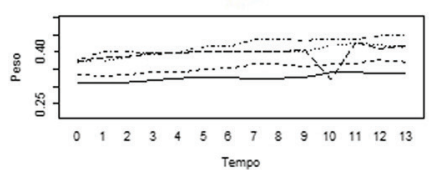

G2

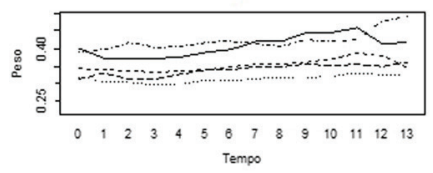

G4

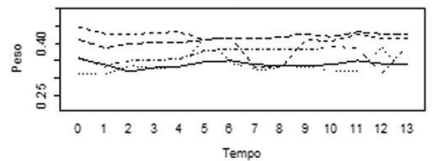

Fig.2. Perfis individuais dos pesos dos ratos ao longo do tempo.

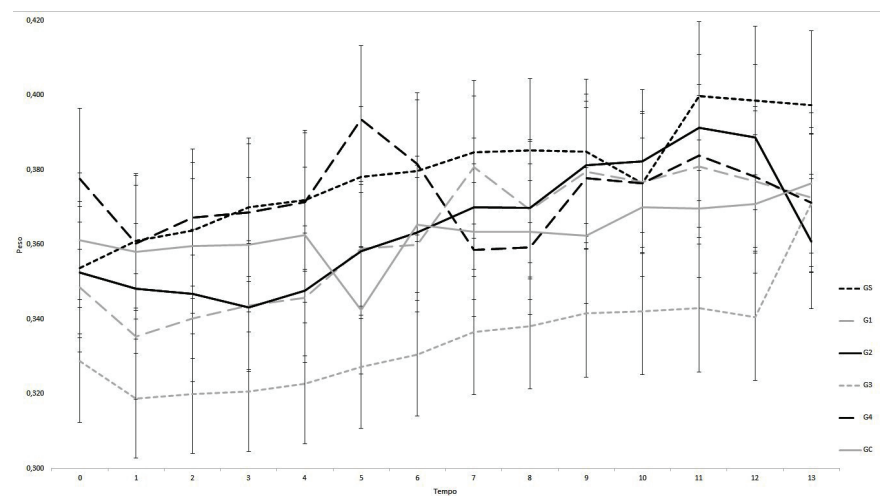

Fig.3. Perfis médios do peso dos ratos ao longo do tempo, por grupo.

(1/30). À necropsia do rato de G1 notaram-se extensas áreas de consolidação pulmonar de distribuição cranioventral, que foram relacionadas à pneumonia por falsa via. Com relação aos achados necroscópicos nos animais dos diferentes grupos, no GS não foram encontradas alterações macroscópicas. Já nos grupos tratados com DOX, com e sem EECP, foi detectada ascite.

As variações de peso não foram significativas (Fig.2 e Fig.3). Também não foram representativas as relações entre o peso final do rato e o peso do coração, assim como entre as medidas dos eixos longitudinal e transversal dos corações, mensurados no momento da necropsia. 0 teste 
não paramétrico de Kruskal-Wallis, para comparação de grupos independentes, não demonstrou diferença entre os grupos para nenhuma das variáveis analisadas: peso final do rato $(\chi 2=4,519 ;$ g.l. $=5$; valor $p=0,477)$, peso do coração $(\chi 2=2,861$; g.l. $=5$; valor $\mathrm{p}=0,721)$, proporção do peso do coração em relação ao peso final dos ratos $(\chi 2=2,892$; g.l. =5; valor $\mathrm{p}=0,717)$, medida longitudinal do coração $(\chi 2=6,781$; g.l. $=5$; valor $\mathrm{p}=0,237)$ e medida transversal do coração $(\chi 2=3,583$; g.l. $=5$; valor $\mathrm{p}=0,611)$ (Quadro 1$)$.

À avaliação histopatológica (Fig.4) observaram-se no coração dos ratos tratados com DOX degeneração vacuolar miocítica, vacuolização da túnica média de artérias e arteríolas, desorganização das fibras, fragmentação das miofibrilas, necrose de coagulação, infiltrado inflamatório predominantemente mononuclear, por vezes com células de Anitschkow, fibrose, congestão e edema. Ao teste Kruskal-Wallis, seguido do teste de Dunn, ao nível de significância de 5\%, observou-se diferença na intensidade de células de Anitschkow ( $p=0,0407)$, sendo que G2 e G4 foram os únicos grupos que não diferiram do GS, indicando menor quantidade des-

Quadro 1. Teste não paramétrico de Kruskal-Wallis, para comparação de grupos independentes, das variáveis peso

final do rato, peso do coração e proporção do peso do coração em relação ao peso final dos ratos (peso do coração /peso final do rato), medidas do coração eixo longitudinal e medidas do coração eixo transversal, por grupo

\begin{tabular}{|c|c|c|c|c|c|c|}
\hline Variável & Grupo & $\mathrm{N}$ & $\begin{array}{l}\text { Média dos } \\
\text { postos }\end{array}$ & $\begin{array}{c}\text { Qui- } \\
\text { quadrado }\end{array}$ & $\begin{array}{l}\text { Grau de } \\
\text { liberdade }\end{array}$ & $\begin{array}{c}\text { Valor } \\
\text { p }\end{array}$ \\
\hline \multirow[t]{7}{*}{ Peso final do rato } & GS & 5 & 19,4 & \multirow[t]{7}{*}{4,519} & \multirow[t]{7}{*}{5} & \multirow[t]{7}{*}{0,477} \\
\hline & G1 & 4 & 15,0 & & & \\
\hline & G2 & 5 & 15,8 & & & \\
\hline & G3 & 5 & 8,4 & & & \\
\hline & G4 & 5 & 16,4 & & & \\
\hline & GC & 5 & 15,0 & & & \\
\hline & Total & 29 & & & & \\
\hline \multirow[t]{7}{*}{ Peso do coração } & GS & 5 & 16,1 & \multirow[t]{7}{*}{2,861} & \multirow[t]{7}{*}{5} & \multirow[t]{7}{*}{0,721} \\
\hline & G1 & 4 & 15,0 & & & \\
\hline & G2 & 5 & 15,9 & & & \\
\hline & G3 & 5 & 9,6 & & & \\
\hline & G4 & 5 & 15,2 & & & \\
\hline & GC & 5 & 18,2 & & & \\
\hline & Total & 29 & & & & \\
\hline \multirow{7}{*}{$\begin{array}{l}\text { Proporção do peso } \\
\text { do coração } \\
\text { em relação ao peso } \\
\text { final dos ratos }\end{array}$} & GS & 5 & 11,8 & \multirow[t]{7}{*}{2,892} & \multirow[t]{7}{*}{5} & \multirow[t]{7}{*}{0,717} \\
\hline & G1 & 4 & 15,3 & & & \\
\hline & G2 & 5 & 14,8 & & & \\
\hline & G3 & 5 & 14,0 & & & \\
\hline & G4 & 5 & 13,8 & & & \\
\hline & GC & 5 & 20,4 & & & \\
\hline & Total & 29 & & & & \\
\hline Medida do coração & GS & 5 & 17,5 & \multirow[t]{7}{*}{6,781} & \multirow[t]{7}{*}{5} & \multirow[t]{7}{*}{0,237} \\
\hline \multirow[t]{6}{*}{ Longitudinal } & G1 & 4 & 16,5 & & & \\
\hline & G2 & 5 & 13,0 & & & \\
\hline & G3 & 5 & 17,5 & & & \\
\hline & G4 & 4 & 13,5 & & & \\
\hline & GC & 5 & 19,2 & & & \\
\hline & Total & $28^{*}$ & & & & \\
\hline Medida do coração & GS & 5 & 12,6 & \multirow[t]{7}{*}{3,583} & \multirow[t]{7}{*}{5} & \multirow{7}{*}{0,611} \\
\hline \multirow[t]{6}{*}{ Transversal } & G1 & 4 & 13,9 & & & \\
\hline & G2 & 5 & 10,5 & & & \\
\hline & G3 & 5 & 14,6 & & & \\
\hline & G4 & 4 & 19,9 & & & \\
\hline & GC & 5 & 16,5 & & & \\
\hline & Total & $28^{*}$ & & & & \\
\hline
\end{tabular}

$\bar{*}$ Uma das 29 amostras foi tratada como parcela perdida. sas células nesses grupos. Também houve diferença para a variável distribuição da degeneração vacuolar miocítica ( $p=0,0218$ ), sendo que G1, G2 e G4 não diferiram do GS. Já G3 e GC diferiram do GS e apresentaram maior distribuição da degeneração vacuolar miocítica (Quadro 2). Quanto à distribuição da variável fragmentação das miofibrilas ( $\mathrm{p}=0,0313)$, o único grupo que não diferiu do GS foi o G4, sendo possível correlacionar efeitos positivos ao EECP à avaliação histopatológica (Quadro 2). Entretanto, quanto à variável distribuição do infiltrado inflamatório houve diferença estatística $(\mathrm{p}=0,0165)$ entre $\mathrm{G} 1$ e os demais grupos (Quadro 2), sendo de maior gravidade em G1.

Foi observada a expressão de MMP2, MMP9, TIMP1 e TIMP2 nos cardiomiócitos de todos os grupos avaliados. Ao nível de significância de $5 \%$, o teste não paramétrico de Kruskal-Wallis identificou diferenças nas variáveis TIMP2 intensidade de células marcadas $(\mathrm{p}=0,035)$ e TIMP2 porcentagem de células marcadas (valor $\mathrm{p}=0,036$ ). Para as variáveis TIMP2 intensidade de células marcadas e TIMP2 porcentagem de células marcadas, os grupos G2 e GC apresentaram diferença dos demais, sendo que G2 apresentou menor intensidade, enquanto GC apresentou maior intensidade (Quadro 3).

Observou-se forte correlação positiva entre TIMP2 e MMP2 para a variável intensidade de imunomarcação no grupo G4, ou seja, quando uma variável aumenta a outra também aumenta (Quadro 4).

Quadro 2. Mediana dos valores obtidos na graduação das alterações histopatológicas para cada grupo, analisados por intensidade (I) e por distribuição (D)

\begin{tabular}{|c|c|c|c|c|c|c|c|c|c|c|c|c|c|c|c|}
\hline \multirow[b]{2}{*}{ Grupo } & \multicolumn{2}{|c|}{ DVM } & \multicolumn{2}{|c|}{ DF } & \multicolumn{2}{|c|}{$\mathrm{F}$} & \multicolumn{2}{|c|}{$\mathrm{NC}$} & \multicolumn{2}{|c|}{ CA } & \multicolumn{2}{|c|}{ II } & \multicolumn{2}{|c|}{$\mathrm{C}$} & FM \\
\hline & I & $\mathrm{D}$ & I & $\mathrm{D}$ & I & D & I & D & I & D & I & D & I & $\mathrm{D}$ & I D \\
\hline GS & $0^{\mathrm{a}}$ & $0^{\mathrm{a}}$ & $0^{\mathrm{a}}$ & 0 & $0^{\mathrm{a}}$ & $0^{\mathrm{a}}$ & $2^{\mathrm{a}}$ & 0 & $0^{\mathrm{a}}$ & $0^{\mathrm{a}}$ & $1^{\mathrm{a}}$ & $1^{b}$ & $1 \mathrm{a}$ & $3^{a}$ & $0^{\mathrm{a}} \quad 0^{\mathrm{a}}$ \\
\hline G1 & $1^{\mathrm{a}}$ & $2^{b}$ & $0^{\mathrm{a}}$ & 0 & $0^{\mathrm{a}}$ & $0^{\mathrm{a}}$ & $1^{\mathrm{a}}$ & $1^{\mathrm{a}}$ & $1^{\mathrm{A}}$ & $1^{\mathrm{a}}$ & $1^{\mathrm{a}}$ & $2^{a}$ & $2^{\mathrm{a}}$ & $3^{\mathrm{a}}$ & $1^{\mathrm{a}} 2^{\mathrm{A}}$ \\
\hline G2 & $1^{\mathrm{a}}$ & $1^{b}$ & $0^{\mathrm{a}}$ & $0^{\mathrm{a}}$ & $0^{\mathrm{a}}$ & $0^{\mathrm{a}}$ & $2^{a}$ & $0^{\mathrm{a}}$ & $1^{b}$ & $1^{\mathrm{a}}$ & $1^{\mathrm{a}}$ & $1^{b}$ & $2^{\mathrm{a}}$ & $3^{a}$ & $2^{\mathrm{a}} 2^{\mathrm{A}}$ \\
\hline G3 & $1^{\mathrm{a}}$ & $2^{\mathrm{A}}$ & $0^{\mathrm{a}}$ & $0^{\mathrm{a}}$ & $0^{\mathrm{a}}$ & $0^{\mathrm{a}}$ & $1^{\mathrm{a}}$ & $1^{\mathrm{a}}$ & $1^{\mathrm{A}}$ & $1^{\mathrm{a}}$ & $1^{\mathrm{a}}$ & $1^{\mathrm{A}}$ & $2^{\mathrm{a}}$ & $3^{a}$ & $2^{\mathrm{a}} 2^{\mathrm{A}}$ \\
\hline G4 & $1^{\mathrm{a}}$ & $2^{b}$ & $0^{\mathrm{a}}$ & $0^{\mathrm{a}}$ & $0^{\mathrm{a}}$ & $0^{\mathrm{a}}$ & $2^{\mathrm{a}}$ & $0^{\mathrm{a}}$ & $1^{b}$ & $1^{\mathrm{a}}$ & $1^{\mathrm{a}}$ & $1^{\mathrm{A}}$ & $2^{\mathrm{a}}$ & $3^{\mathrm{a}}$ & $2^{\mathrm{a}} 2^{\mathrm{b}}$ \\
\hline $\mathrm{GC}$ & $1^{\mathrm{a}}$ & $2^{\mathrm{A}}$ & $0^{\mathrm{a}}$ & $0^{\mathrm{a}}$ & $0^{\mathrm{a}}$ & $0^{\mathrm{a}}$ & $1^{\mathrm{a}}$ & $1^{\mathrm{a}}$ & $1^{\mathrm{A}}$ & $1^{\mathrm{a}}$ & $1^{\mathrm{a}}$ & $1^{\mathrm{A}}$ & $2^{\mathrm{a}}$ & $3^{a}$ & $2^{\mathrm{a}} 2^{\mathrm{A}}$ \\
\hline
\end{tabular}

DVM: degeneração vacuolar miocítica, DF: desorganização das fibras, F: fibrose, NC: necrose de coagulação, CA: células de Anitschkow, II: infiltrado inflamatório, C: congestão, FM: fragmentação de miofibrilas. Letras diferentes na mesma coluna não diferem entre si. Letras iguais que diferem em maiúsculas e minúsculas diferem entre si. Letras idênticas não diferem entre si. Teste Kruskal-Wallis, seguido do teste de Dunn, ao nível de significância de 5\%.

Quadro 3. Médias dos postos (ranks) entre TIMP1, TIMP2, MMP2 e MMP9 para os grupos analisados por intensidade e por porcentagem de células marcadas

\begin{tabular}{|c|c|c|c|c|c|c|c|c|}
\hline \multirow[t]{2}{*}{ rup } & \multicolumn{4}{|c|}{ Intensidade } & \multicolumn{4}{|c|}{$\%$ cel marcadas } \\
\hline & TIMP1 & TIMP2 & MMP2 & MMP9 & TIMP1 & כ2 & MMP & MMP9 \\
\hline GS & & & & & & & & \\
\hline G1 & & 16, & & & & & & \\
\hline $\mathrm{G}$ & & & & & & & & $14,00^{\mathrm{a}}$ \\
\hline G: & $11,50^{\mathrm{a}}$ & 12,2 & & & & 11. & $14,00^{\mathrm{a}}$ & $17,00^{\mathrm{a}}$ \\
\hline $\mathrm{G}^{2}$ & $10,00^{\mathrm{a}}$ & 5, & $a^{a}$ & & $0^{\mathrm{a}}$ & $14,50^{\mathrm{ab}}$ & $18,80^{\mathrm{a}}$ & $14,00^{\mathrm{a}}$ \\
\hline $\mathrm{GC}$ & $20,50^{\mathrm{a}}$ & $25,10^{\text {a }}$ & $18,60^{\mathrm{a}}$ & $14,00^{\mathrm{a}}$ & $16,2^{\mathrm{a}}$ & $23,50^{a}$ & 13,90 & $14,00^{\mathrm{a}}$ \\
\hline
\end{tabular}

Letras iguais na mesma coluna não diferem entre si pelo teste de Comparações múltiplas, com correção de Bonferroni, da variável TIMP2 e teste de U-Mann Whitney $(\mathrm{p}<0,05)$. 

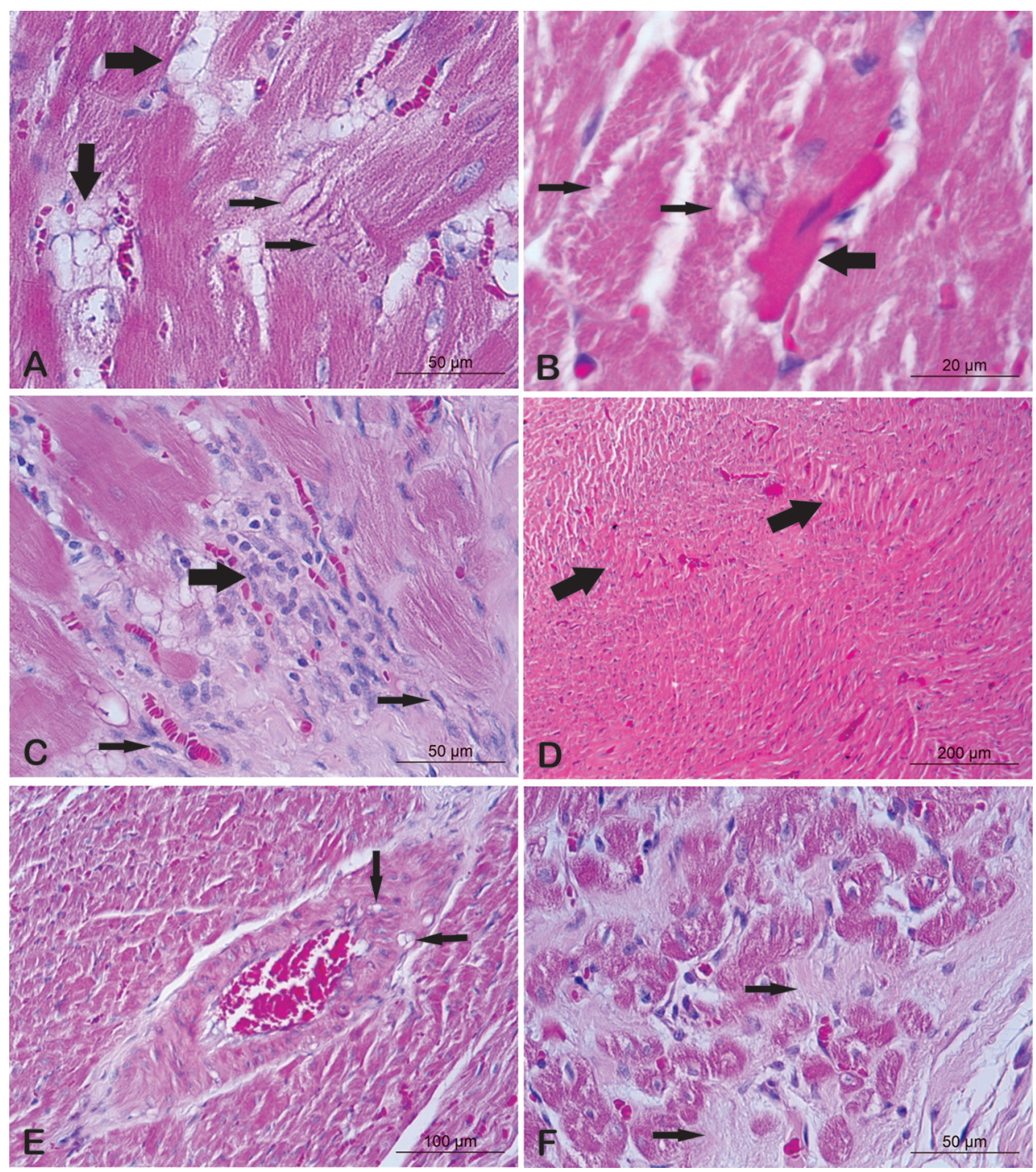

Fig.4. Miocárdio de ratos submetidos à cardiotoxicidade crônica pela DOX. (A) GC = degeneração vacuolar (setas grossas) e fragmentação de miofibrilas (setas finas); (B) G3 = necrose evidenciada por aumento de eosinofilia citoplasmática e picnose nuclear (seta grossa) e fragmentação de miofibrilas (setas finas); (C) G1 = Infiltrado inflamatório predominantemente mononuclear (seta grossa) com células de Anitschkow (setas finas); (D) GC = desorganização de fibras (setas); (E) G4 = vacuolização da túnica média arterial (setas); (F) G1 = fibrose (setas) (HE).

Quadro 4. Correlação de Spearman entre as variáveis avaliadas, por porcentagem de células marcadas e intensidade de imunomarcação, para cada grupo.

\begin{tabular}{|c|c|c|c|c|c|c|c|c|c|c|c|c|}
\hline \multirow{3}{*}{$\begin{array}{l}\text { Correlação de } \\
\text { Spearman }\end{array}$} & \multicolumn{12}{|c|}{ Grupos } \\
\hline & \multicolumn{2}{|c|}{ GS } & \multicolumn{2}{|c|}{ G1 } & \multicolumn{2}{|c|}{ G2 } & \multicolumn{2}{|c|}{ G3 } & \multicolumn{2}{|c|}{ G4 } & \multicolumn{2}{|c|}{ GC } \\
\hline & $\mathrm{R}$ & $\mathrm{P}$ & $\mathrm{R}$ & $\mathrm{P}$ & $\mathrm{R}$ & $\mathrm{P}$ & $\mathrm{R}$ & $\mathrm{P}$ & $\mathrm{R}$ & $\mathrm{P}$ & $\mathrm{R}$ & $\mathrm{P}$ \\
\hline TIMP1/TIMP2 & 0,41 & 0,495 & 0,00 & 1,000 & . & & 0,19 & 0,764 & 0,65 & 0,239 & . & \\
\hline$\approx$ TIMP1/MMP2 & 0,19 & 0,764 & $-0,79$ & 0,111 & $-0,25$ & 0,685 & $-0,81$ & 0,100 & $-0,79$ & 0,111 & $-0,79$ & 0,111 \\
\hline घี TIMP1/MMP9 & $-0,25$ & 0,685 & 0,00 & 1,000 & . & . & $-0,56$ & 0,327 & & 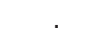 & 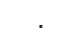 & . \\
\hline 巴্] TIMP2/MMP2 & $-0,76$ & 0,135 & $-0,41$ & 0,495 & . & . & 0,19 & 0,764 & $-0,41$ & 0,495 & . & . \\
\hline ¿ TIMP2/MMP9 & $-0,61$ & 0,272 & $-0,61$ & 0,272 & . & . & $-0,25$ & 0,685 & . & . & . & . \\
\hline MMP2/MMP9 & 0,75 & 0,148 & 0,25 & 0,685 & . & . & 0,75 & 0,148 & . & . & . & . \\
\hline TIMP1/TIMP2 & 0,15 & 0,807 & 0,00 & 1,000 & . & . & $-0,25$ & 0,685 & 0,75 & 0,144 & 0,00 & 1,000 \\
\hline TIMP1/MMP2 & 0,30 & 0,619 & $-0,40$ & 0,510 & . & . & $-0,56$ & 0,327 & 0,65 & 0,239 & 0,57 & 0,312 \\
\hline$\cong$ TIMP1/MMP9 & $-0,75$ & 0,148 & $-0,40$ & 0,510 & . & 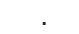 & $-0,25$ & 0,685 & . & . & & . \\
\hline 吉 TIMP2/MMP2 & $-0,67$ & 0,219 & $-0,41$ & 0,495 & . & . & 0,19 & 0,764 & 0,97 & 0,007 CR & $-0,41$ & 0,498 \\
\hline$=$ TIMP $2 / \mathrm{MMP} 9$ & $-0,61$ & 0,272 & $-0,61$ & 0,272 & . & . & $-0,25$ & 0,685 & . & . & . & . \\
\hline MMP2/MMP9 & 0,41 & 0,495 & 0,25 & 0,685 & 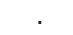 & . & 0,75 & 0,148 & . & 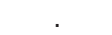 & 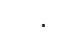 & \\
\hline
\end{tabular}

CR Forte correlação positiva entre TIMP2 e MMP2

R: Correlação entre as variáveis avaliadas.

P: Valor de p. 


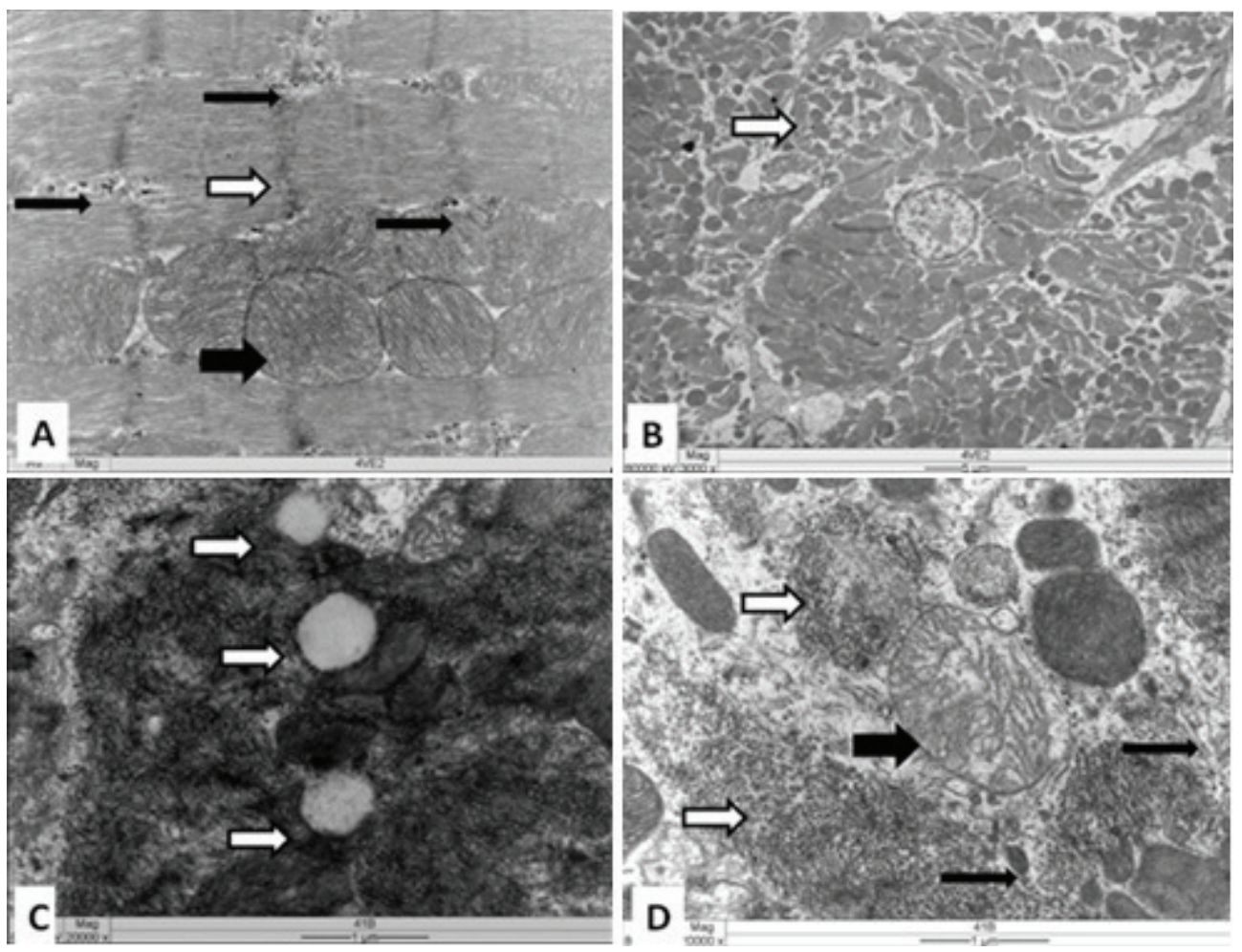

Fig.5. Ultramicrografias do miocárdio de rato. (A) Grupo Sham = tecido cardíaco normal, notar miofibrilas bem organizadas (seta branca), sem vacúolos, mitocôndrias morfologicamente normais (seta grossa) e grânulos de glicogênio (setas pretas finas); (B) Grupo G3 = edema, notar maior espaçamento entre miofibrilas (setas); (C) Grupo G3 = vacúolos (setas); (D) Grupo G4 = necrose, desorganização de miofibrilas (seta branca), desestruturação das mitocôndrias (seta preta grossa) e debris de organelas (setas pretas finas). Cortes contrastados com uranila e citrato de chumbo.

Quanto aos achados ultramicroscópicos, os cardiomiócitos de ratos do GS apresentaram poucos vacúolos, organelas morfologicamente normais e miofibrilas organizadas (Fig.5A). Já nas células miocárdicas de ratos dos grupos G3 e G4 havia edema, focos de necrose, além de tumefação das cristas mitocondriais, desorganização de miofibrilas e numerosos vacúolos (Fig.5C e Fig.5D). No coração dos animais dos grupos G1, G2 e GC não foram identificadas áreas de necrose, notaram-se menos vacúolos, raras mitocôndrias tumefeitas e dilatação de retículo endoplasmático liso (REL).

\section{DISCUSSÃO}

0 teor de umidade da amostra de EECP foi 9,03\% $\pm 0,283$. Oliveira et al. (1998) afirmam que matérias-primas vegetais com teores de umidade abaixo de $14 \%$ apresentam baixos riscos de desenvolvimento microbiológico. A umidade das amostras vegetais está relacionada às estabilidades física, química e microbiológica. Desse modo, o teor de umidade encontrado para o extrato vegetal de Caryocar brasiliensis está dentro dos padrões de qualidade para o produto. 0 teor de umidade é influenciado pelo plantio (ambiente), colheita, armazenamento e tratamento prévio do vegetal. Já os teores de cinzas totais do EECP foram 5,87\% $\pm 0,06$. Os teores de cinzas totais representam a quantidade de minerais essenciais para a formação do vegetal. Entretanto, representa também possível contaminação com impurezas inorgânicas, a exemplo de metais e sílica.

A avaliação granulométrica do material vegetal moído caracterizou-o como pó grosso (Brasil 2010). Conforme
List \& Schmidt (2000), partículas de tamanho superior à classificação de fino são adequadas para os processos de extração. Assim, o pó utilizado neste estudo se mostrou adequado para o processo de extração, tendo as características desejadas para evitar a formação de canais preferenciais ou empacotamento da amostra no processo de percolação.

Com relação aos índices de mortalidade, houve morte de um único rato neste experimento, por falhas operacionais, semelhante ao descrito por Xin et al. (2011) ao utilizar $10 \mathrm{mg} / \mathrm{kg}$ de DOX, por via intraperitoneal, em dose única. Por outro lado, Kizaki et al. (2006) utilizaram dose única de $25 \mathrm{mg} / \mathrm{kg}$ de DOX em ratos e avaliaram índices de mortalidade um, dois e quatro dias após a aplicação da DOX. Após um e dois dias não houve mortalidade. Já o grupo que foi submetido à eutanásia quatro dias após a aplicação apresentou taxa de mortalidade de $29 \%$. Índices ainda maiores, acima de 50\% de mortalidade, foram descritos por Ferreira et al. (2007) ao acumular $16 \mathrm{mg} / \mathrm{kg}$ de DOX. Neste estudo, a ausência de mortalidade relacionada ao fármaco se deve, possivelmente, à menor dose de DOX utilizada e ao intervalo de tempo decorrido entre os tratamentos e a necropsia.

Quanto aos achados necroscópicos, no GS não foram encontradas alterações macroscópicas. Entretanto, nos grupos tratados com DOX, com e sem o EECP, foi detectada ascite em alguns animais. Achados semelhantes foram descritos por Ferreira et al. (2007), que notaram acúmulo de líquido seroso no pericárdio e cavidade peritoneal de ratos 
tratados com $16 \mathrm{mg} / \mathrm{kg}$ de DOX, pelo mesmo intervalo de tempo e via de aplicação utilizados neste estudo. Na presente pesquisa, esses resultados podem estar relacionados aos danos aos cardiomiócitos induzidos pela DOX. Entretanto, assim como Ferreira et al. (2007), não se descarta a possibilidade desse achado estar relacionado a danos renais, ou até mesmo hepáticos, induzidos pelo quimioterápico, já que esses órgãos não foram avaliados.

Não foi observada alteração no peso e nas medidas do coração dos ratos. Pontes et al. (2010) avaliaram lesões cardíacas macroscópicas em ratos seis meses após a aplicação de $5 \mathrm{mg} / \mathrm{kg}$ de DOX. Notaram que o coração dos animais aumentou $41 \%$ em relação ao peso, 33\% no diâmetro interno, $14 \%$ no diâmetro externo e $24 \%$ na espessura da parede do ventrículo esquerdo. Esperava-se que, com a aplicação de uma dose maior de DOX (8mg/kg), achados semelhantes pudessem ser obtidos, em intervalo de tempo menor, o que não ocorreu. Portanto, essa diferença se deve provavelmente à marca da doxorrubicina utilizada e ao tempo decorrido entre a aplicação da DOX e a mensuração dessas variáveis, no momento da eutanásia, já que na presente pesquisa a avaliação foi conduzida dois meses após a última aplicação de DOX.

Neste estudo, as alterações histopatológicas encontradas no coração dos ratos dos grupos tratados com DOX foram degeneração vacuolar miocítica, vacuolização da túnica média de artérias e arteríolas, desorganização das fibras, fragmentação das miofibrilas, necrose de coagulação, infiltrado inflamatório predominantemente mononuclear, por vezes com células de Anitschkow (macrófagos), fibrose, congestão e edema. Já Pontes et al. (2010) relatam fibrose, vacuolização citoplasmática dos miócitos, necrose miocárdica e variação no tamanho nuclear, que também foram observados neste estudo, exceto a variação no tamanho nuclear, que acompanha a hipertrofia muscular relatada pelos autores, a qual não foi identificada no coração dos ratos desta pesquisa.

Resultados semelhantes ao desta pesquisa foram descritos por Ferreira et al. (2007) ao administrar $4 \mathrm{mg} / \mathrm{kg}$ de DOX, em ratos, por via intraperitoneal, durante quatro semanas, totalizando $16 \mathrm{mg} / \mathrm{kg}$. As alterações descritas pelos autores foram desorganização de miofibrilas, vacuolização dos miócitos, edema intersticial, necrose (evidenciada por picnose nuclear, cariorrexe e cariólise) e infiltrado mononuclear. Também Iqbal et al. (2008), ao utilizar $20 \mathrm{mg} / \mathrm{kg}$ de DOX por via intraperitoneal, em dose única, notaram ruptura das miofibrilas, elevado número de células inflamatórias e discreto edema dois dias após a aplicação de DOX; e necrose focal da fibra muscular, com edema, hemorragia e congestão, após sete dias da aplicação. Por outro lado, Karimi et al. (2005) encontraram degeneração miocárdica focal, acompanhada de infiltrado de células mononucleares após aplicar dose única de $15 \mathrm{mg} / \mathrm{kg}$, em camundongos, via intraperitoneal e realizar eutanásia três dias após a aplicação da DOX. Essas alterações foram de menor intensidade que as encontradas no miocárdio dos animais deste experimento. Esses resultados indicam que a cardiotoxicidade pode estar relacionada ao intervalo de tempo entre a aplicação da DOX e a avaliação morfológica.
0 extrato etanólico da casca do pequi (EECP) demonstrou ser eficiente por minimizar os efeitos deletérios da DOX no miocárdio de ratos, especialmente quando na dose de $600 \mathrm{mg} / \mathrm{kg}$, conforme utilizado nos grupos G2 e G4. No grupo G1 a degeneração vacuolar foi atenuada. Em G2 a degeneração vacuolar foi atenuada e houve redução do número de células de Anitschkow. Em G4 a degeneração vacuolar foi atenuada, houve redução do número de células de Anitschkow e redução na fragmentação das miofibrilas. No que se refere ao uso de antioxidantes na tentativa de atenuar danos aos cardiomiócitos induzidos pela DOX, achados semelhantes foram descritos por Abdel-Raheeme \& Abdel-Ghany (2009) e Walker et al. (2011) ao testar hesperidin e probucol, respectivamente, os quais relataram que o uso desses antioxidantes minimiza os danos induzidos pela DOX.

Quanto à varivável infiltrado inflamatório, apesar desta não ter sido de grande intensidade, resultados de maior gravidade foram encontrados no G1. Embora fossem esperados danos maiores ao coração dos ratos de GC, grupo que não recebeu EECP, acredita-se que compostos presentes no EECP tenham induzido resposta inflamatória, iniciada logo no pré-tratamento, já que os de G3 também receberam $300 \mathrm{mg} / \mathrm{kg}$ do EECP, porém somente como tratamento, após a aplicação de DOX, e não apresentaram o mesmo resultado. Após a aplicação da DOX é possível que ocorra biotransformação de derivados e rearranjos destes, resultando em novos produtos de transformação química (Oliveira 2013).

Acredita-se que o equilíbrio anti-inflamatório possa ser alcançado com doses maiores do referido extrato, já que nos grupos que receberam $600 \mathrm{mg} / \mathrm{kg}$ havia pouco infiltrado. Ensaios pré-clínicos demonstraram propriedades anti-inflamatórias do óleo do pequi. Nesse sentido, Oliveira (2013) investigou a atividade antinociceptiva e anti-inflamatória do óleo de pequi na artrite induzida por zymosan em ratos. 0 autor sugere que o óleo do pequi exibe efeito anti-inflamatório, que pode estar associado à inibição de citocinas pró-inflamatórias. Nesse estudo realizado por Oliveira (2013), a redução do número de leucócitos ocorreu de forma mais acentuada nos tratamentos que acumularam doses diárias do que nos tratamentos com dose única, corroborando os resultados da presente pesquisa.

Ao avaliar a imunomarcação de MMP e TIMP, todas essas proteínas foram imunomarcadas nos cardiomiócitos dos ratos de todos os grupos, incluindo os do GS. Esses achados são compatíveis com os apontamentos de Li et al. (2000) ao afirmarem que as MMP estão presentes no miocárdio e são capazes de degradar todos os componentes da MEC do coração. Opostos aos resultados deste estudo são os de Adamcová et al. (2010), que pesquisaram o remodelamento cardíaco e a imunomarcação de MMP em modelo experimental de cardiomiopatia crônica por Daunorrubicina (DAU), uma ANT da família da DOX, em coelhos. No grupo Sham, a marcação de MMP2 (72kd) não foi detectada imunoistoquimicamente. Acredita-se que os resultados divergentes possivelmente estejam relacionados aos anticorpos utilizados, espécie envolvida e diluições utilizadas. Ainda, os autores detectaram maior imunoexpressão de MMP2 nos grupos tratados apenas com DAU em cardiomiócitos e 
fibroblastos em focos de dano tóxico significativo, e, dessa forma, puderam correlacionar efeitos positivos ao dexrazoxane, o que também não ocorreu na presente pesquisa.

No presente estudo não foram identificados resultados significativos quanto à imunomarcação das MMP. Quanto aos TIMP, os resultados da imunomarcação de anti-TIMP2 foram maiores nos animais de GC, grupo que recebeu apenas DOX e menores nos de G2, grupo que recebeu a maior dose do extrato, durante mais tempo. TIMP2 estava altamente expresso no grupo que não recebeu antioxidante e acredita-se que o aumento da sua marcação tecidual esteja relacionado a sua ação como ativador das MMP, já que TIMP2 é o único membro das TIMP capaz de atuar como ativador e inibidor das MMP (Bourboulia \& Stetler-Stevenson 2010). À semelhança dos resultados no que se refere à imunomarcação de TIMP2, Reinhardt et al. (2002) avaliaram in vitro a influência de inibidores da enzima conversora de angiotensina na expressão de TIMP2 em pacientes com insuficiência cardíaca, decorrentes de doença obstrutiva coronariana e de cardiomiopatia dilatada idiopática, comparada ao grupo Sham. Demonstraram que TIMP2 estava altamente expresso em todos os grupos, com tendência a aumentar sua imunomarcação nos corações doentes, conforme também observado no presente estudo.

Embora inicialmente fosse esperada imunomarcação aumentada de MMP2 nos grupos tratados com DOX, já que o estresse oxidativo pode ativar MMP e que TIMP2 pode ativar MMP2 (Bourboulia \& Stetler-Stevenson 2010), Ivanová et al. (2012), ao estudar ratos com cardiomiopatia induzida por DOX, encontraram aumento na atividade miocárdica da pro-MMP2 apenas oito semanas após a indução, quando havia acumulado a dose de $15 \mathrm{mg} / \mathrm{kg}$. Na presente pesquisa, apesar de a dose total acumulada ter sido $8 \mathrm{mg} / \mathrm{kg}$, inferior à dose acumulada no citado estudo, acredita-se que o fator tempo possua grande influência na expressão dessas proteínas, fato também relatado por Ivanová et al. (2012). Nesse sentido, experimentos têm sido realizados buscando estabelecer curvas de expressão dessas proteínas, correlacionando-as com o tempo pós-aplicação da DOX. Kizaki et al. (2006) investigaram a expressão de MMP2 e MMP9 no ventrículo um, dois e quatro dias após indução de cardiotoxicidade pela DOX, com dose única de $25 \mathrm{mg} / \mathrm{kg}$. Notaram que houve aumento na imunomarcação de MMP2 e MMP9 no dia dois. MMP2 praticamente dobrou a expressão nos camundongos tratados com DOX nos dias um e dois. Por outro lado, MMP9 não diferiu em nenhum grupo no dia um e aumentou significativamente nos tratados nos dias dois e quatro.

A imunomarcação de MMP9 em todos os grupos, apesar de presente em alguns animais, foi discreta e notavelmente inferior à marcação dos demais anticorpos utilizados (MMP2, TIMP1 e TIMP2). Em concordância a esses resultados, Adamcová et al. (2010) não identificaram formas inativas e/ou ativas de MMP9 no tecido miocárdico. Esses dados sugerem que a MMP9 não participa na cardiotoxicidade crônica induzida pela DOX, o que pode estar relacionado a ausência de infiltrado inflamatório típico, já que essa enzima está associada a leucócitos (Reinhardt et al. 2002) e o infiltrado inflamatório, apesar de observado, não foi relevante. De modo semelhante, Ivanová et al. (2012) também não encontraram formas inativas e/ou ativas da MMP9 no tecido cardíaco de ratos. Por outro lado, Aupperle et al. (2007), por meio de imunoistoquímica, encontrou aumento na imunomarcação de MMP1, MMP2 e MMP9 em cardiomiócitos de coelhos com cardiomiopatia induzida por DOX, comparativamente aos animais do grupo Sham.

Quanto aos achados ultramicroscópicos, notaram-se, nos grupos tratados com DOX, edema, dilatação do retículo sarcoplasmático, vacuolização citoplasmática, edema mitocondrial e necrose. Nascimento \& Martins (2005) relataram lesões cardíacas ultramicroscópicas induzidas pela DOX semelhantes às descritas nesta pesquisa. Resultados semelhantes também foram descritos por Khan et al. (2005), em camundongos tratados com dose acumulada de $16 \mathrm{mg} / \mathrm{kg}$ de DOX, por via intraperitoneal. Por outro lado, Dudnakova et al. (2003), em análise ultramicroscópica, três semanas após a aplicação de 2,2mg/kg de DOX, observaram perda focal de elementos contráteis, alterações no citoesqueleto e drástica alteração na permeabilidade nuclear nos cardiomiócitos de ratos tratados com DOX, alterações estas não detectadas na presente pesquisa, o que pode estar relacionado à dose e ao tempo decorrido entre a aplicação da DOX e a avaliação morfológica.

Em análise comparativa dos grupos, nos animais de G1, G2 e GC não foram identificadas áreas de necrose, havia menor quantidade de vacúolos e raras mitocôndrias tumefeitas. Já nos ratos dos grupos G3 e G4 havia focos de necrose, edema mitocondrial e vacuolização citoplasmática. Nos ratos dos grupos que receberam pré-tratamento com o EECP (G1 e G2) houve alterações ultramicroscópicas semelhantes às do grupo que recebeu apenas DOX. Por outro lado, nos grupos G3 e G4, que receberam EECP durante o tratamento com DOX nas doses de 300 e $600 \mathrm{mg} / \mathrm{kg}$, respectivamente, as lesões foram mais acentuadas. Acredita-se que esses resultados estejam relacionados à pequena área tecidual avaliada pela técnica de microscopia eletrônica. Apesar de cinco fragmentos terem sido colhidos de cada coração, cada corte media apenas $1 \mathrm{~mm}$. Ao correlacionar esses achados aos resultados histopatológicos, a histopatologia possibilitou ampla avaliação do tecido, ao passo que a microscopia eletrônica evidenciou detalhes ultramicroscópicos que auxiliaram no diagnóstico. Entretanto, não se descarta a possibilidade da presença de substâncias tóxicas na casca do pequi e, para assegurar o uso do EECP em humanos e animais, é imprescindível a realização de testes direcionados ao efeito tóxico e análise da composição química desse vegetal.

Ao confrontar os resultados dos grupos de administração do EECP com outros extratos de frutos também ricos em antioxidantes, efeitos semelhantes foram encontrados. Khan et al. (2005) relataram que a Spirulina protegeu significativamente camundongos dos efeitos cardiotóxicos da DOX. Xin et al. (2011) relataram que o pré-tratamento com polissacarídeo de Lycium barbarum reduziu significativamente o estresse oxidativo induzido pela DOX no tecido cardíaco. Também, Abdel-Raheem \& Abdel-Ghany (2009) relataram que o Hesperidin, um bioflavonoide presente em frutas cítricas, minimizou os efeitos deletérios da DOX.

No presente estudo não foram realizados ensaios para avaliar a atividade antioxidante do extrato etanólico do 
pequi. Apesar disso, os efeitos deletérios da DOX foram minimizados com o uso do extrato. Nesse contexto, embora se não se possa afirmar, sugere-se a possibilidade que tais efeitos se devam às propriedades antioxidantes do referido fruto. Essa hipótese pauta-se no fato de que Lima (2008), ao avaliar a atividade antioxidante do extrato da polpa e da amêndoa do pequi por ensaios de co-oxidação do $\beta$-caroteno, DPPH (radical 1,1-diphenil-2-picrilhydrazil), ABTS - 2,2'-azino-bis(3-ethylbenzthiazoline-6-sulfonic acid), ORAC (Capacidade de Absorção de Radicais Oxigênio) e Rancimat, notou que o pequi apresenta expressiva atividade antioxidante. Avaliou ainda a composição em ácidos fenólicos por HPLC e detectou ácido elágico, gálico, 4-OH benzoico, p-cumárico e procianidina B2. Também Roesler et al. (2007) pesquisaram a atividade antioxidante de extratos aquosos e etanólicos em frações de diferentes frutos (polpa, semente e casca) do bioma cerrado, entre os quais o pequi (Caryocar brasilense). Os extratos com altíssimos conteúdos de compostos fenólicos foram escolhidos para a avaliação do potencial em sequestrar radicais livres pelo modelo 2,2 difenil-1-picril hidrazil (DPPH). Os extratos, aquoso e etanólico, de casca do pequi mostraram os melhores resultados, indicando que o extrato etanólico da casca do pequi possui grande potencial antioxidante.

\section{CONCLUSÕES}

Concluiu-se que o extrato etanólico da casca do pequi (EECP) é eficiente em minimizar os efeitos da cardiotoxicidade crônica induzida pela DOX no miocárdio de ratos, considerando que nas doses de 300 e $600 \mathrm{mg} / \mathrm{kg}$ o extrato atenua a degeneração vacuolar miocítica e, na dose de $600 \mathrm{mg} /$ $\mathrm{kg}$, o mesmo reduz a quantidade de células de Anitschkow e a fragmentação das miofibrilas.

Outros órgãos como rins, fígado, medula óssea e o trato gastrintestinal são passíveis de lesões induzidas pela DOX, e, por isso, podem ser alvo para futuras investigações.

Sugere-se a avaliação do EECP em diferentes vias de aplicação, em diversas espécies animais, diferentes dosagens, especialmente superiores às utilizadas neste estudo.

Agradecimentos.- Os autores agradecem à Coordenação de Aperfeiçoamento de Pessoal de Nível Superior (CAPES) pela bolsa de doutorado concedida e ao Conselho Nacional de Desenvolvimento Científico e Tecnológico (CNPq), pelo apoio financeiro.

\section{REFERÊNCIAS}

Abdel-Raheem I.T. \& Abdel-Ghany A.A. 2009. Hesperidin alleviates doxorubicin-induced cardiotoxicity in rats. J Egypt Natl Canc. Inst. 21(2):175184.

Adamcová M., Potácová A., Popelová O., Stěrba M., Mazurová Y., Aupperle H. \& Geršl V. 2010. Cardiac remodeling and MMPs on the model of chronic daunorubicin-induced cardiomyopathy in rabbits. Physiol Res. 59(5):831-832.

Aguilar E.C., Jascolka T.L., Teixeira L.G., Lages P.C., Ribeiro A.C.C., Vieira E.L.M., Peluzio M.C.G. \& Alvarez-Leite J.I. 2012. Paradoxical effect of a pequi oil-rich diet on the development of atherosclerosis: balance between antioxidant and hyperlipidemic properties. Braz. J. Med. Biol. Res. 45(7):601-609.

Aupperle H., Garbade J., Schubert A., Barten M., Dheins S., Schoon H.A. \& Mohr F.W. 2007. Effects of autologous stem cells on immunohistochemi- cal patterns and gene expression of metalloproteinases and their tissue inhibitors in doxorubicin cardiomyopathy in a rabbit model. Vet Pathol. 44:494-503.

Barreiro A.L.B.S., David J.M. \& David J.P. 2006. Estresse oxidativo: relação entre geração de espécies reativas e defesa do organismo. Química Nova. 29(1):113-126.

Bourboulia D. \& Stetler-Stevenson W.G. 2010. Matrix MetalloProteinases (MMPs) and Tissue Inhibitors of MetalloProteinases (TIMPs): positive and negative regulators in tumor cell adhesion. Semin. Cancer Biol. 20(3):161-168. doi:10.1016/j.semcancer.2010.05.002

Brasil 2010. Farmacopeia Brasileira. Vol.1. 5a ed. Agência Nacional de Vigilância Sanitária, Brasília.

Brehmer B., Biesterfeld S. \& Jakse G. 2003. Expression of matrix metalloproteinases (MMP2 and -9) and their inhibitors (TIMP1 and -2) in prostate cancer tissue. Prostate Cancer Prostatic Dis. 6(3):217-222.

Brew K., Dinakarpandian D. \& Nagase H. 2007. Tissue inhibitors of metalloproteinases: evolution, structure and function: a review. Biochim Biophys Acta. 1477(1/2):267-283.

Díez J. 2010. Altered degradation of extracellular matrix in myocardial remodelling: the growing role of cathepsins and cystatins. Cardiovasc. Res. 87(4):591-592. doi: $10.1093 / \mathrm{cvr} / \mathrm{cvq} 208$

Dudnakova T.V., Lakomkin V.L., Tsyplenkova V.G., Shekhonin B.V., Shirinsky V.P. \& Kapelko V.I. 2003. Alterations in myocardial cytoskeletal and regulatory protein expression following a single Doxorubicin injection. J. Cardiovasc. Pharmacol. 41(5):788-794.

Faleiro M.B.R., Croce G.B., Toledo D.C., Rodrigues M.M.P., Batista A.C., Damasceno A.D., Brito L.A.B., Amorim R.L. \& Moura V.M.B.D. 2013. Matrix metalloproteinases 2 and 9 expression in canine normal prostate and with proliferative disorders. Ciência Rural 43(6):1037-1043.

Ferreira A.L., Russell R.M., Rocha N., Placido Ladeira M.S., Favero Salvadori D.M., Oliveira Nascimento M.C., Matsui M., Carvalho F.A., Tang G., Matsubara L.S. \& Matsubara B.B. 2007. Effect of lycopene on doxorubicin-induced cardiotoxicity: an echocardiographic, histological and morphometrical assessment. Basic Clin. Pharmacol. Toxicol. 101(1): 16-24.

Iqbal M., Dubey K., Anwer T., Ashish A. \& Pillai K.K. 2008. Protective effects of telmisartan against acute doxorubicin-induced cardiotoxicity in rats. Pharmacol Rep. 60(3):382-390. Disponível em <http://www.if-pan. krakow.pl/pjp/pdf/2008/3_382.pdf>. Acesso em: 23 jun. 2013.

Ivanová M., Dovinová I., Okruhlicová L., Tribulová N., Šimončíková P., Barteková M., Vlkovičová J. \& Barančík M. 2012. Chronic cardiotoxicity of doxorubicin involves activation of myocardial and circulating matrix metalloproteinases in rats. Acta Pharmacol. Sin. 33:459-469.

Karimi G., Ramezani M. \& Abdi A. 2005. Protective effects of lycopene and tomato extract against doxorbicin-induced cardiotoxicity. Phytother. Res. 19(10):912-914.

Khan M., Shobha J.C., Mohan I.K., Naidu M.U., Sundaram C., Singh S., Kuppusamy P. \& Kutala V.K. 2005. Protective effect of Spirulina against doxorubicin-induced cardiotoxicity. Phytother. Res. 19(12):1030-1037.

Khasigov P.Z., Podobed O.V., Gracheva T.S., Salbiev K.D., Grachev S.V. \& Berezov T.T. 2003. Role of matrix metalloproteinases and their inhibitors in tumor invasion and metastasis: a review. Biochemistry (Mosc) 68(7):711-717.

Kizaki K., Ito R., Okada M., Yoshioka K., Uchide T., Temma K., Mutoh K., Uechi M. \& Hara Y. 2006. Enhanced gene expression of myocardial matrix metalloproteinases 2 and 9 after acute treatment with doxorubicin in mice. Pharmacol. Res. 53(4):341-346.

Kuskoski E.M., Asuero A.G., Troncoso A.M., Mancini-Filho J. \& Fett R. 2005. Aplicación de diversos métodos químicos para determinar actividad antioxidante em pulpa de frutos. Ciências e Tecnologia de Alimentos 25(4):726-732.

Li Y.Y., McTiernan C.F. \& Feldman A.M. 2000. Interplay of matrix metalloproteinases, tissue inhibitors of metalloproteinases and their regulators in cardiac matrix remodeling; a review. Cardiovasc. Res. 46(2):214224.

Lima A. 2008. Caracterização química, avaliação da atividade antioxidante 
in vitro e in vivo, e identificação dos compostos fenólicos presentes no pequi (Caryocar brasiliense Camb.). Tese de Doutorado, Universidade de São Paulo, São Paulo. Disponível em <www.teses.usp.br/teses/disponiveis/9/9131/tde-30042008.../Tese.pdf.> Acesso em 13 abr. 2015.

List P.H., Schmidt P.C. 2000. Phytopharmaceutical Technology. CRC Press, Florida.

Miguel M.P., Menezes L.B. \& Araújo E.G. 2012. Fisiopatologia do estresse oxidativo após isquemia e reperfusão cerebral e potencial neuroproteção do pequi (Caryocar brasiliense). Enciclopédia Biosfera 8(15):19601976.

Nabeshima K., Inoue T., Shimao Y. \& Sameshima T. 2002. Matrix metalloproteinases in tumor invasion: role for cell migration. Pathol. Int. 52(4):255-264.

Nascimento M.C.M.O. \& Martins A.S. 2005. Cardiomiopatia induzida pela adriamicina: uma revisão. Arq. Ciênc. Saúde 12(2):111-115.

Oliveira F.F.B. 2013. Efeito antinociceptivo e anti-inflamatório do óleo da polpa de pequi Caryocar coriaceum Wittm na artrite induzida por zymosan em ratos. Dissertação de Mestrado, Universidade Federal do Ceará, Fortaleza. Disponível em <www.repositorio.ufc.br/ri/bitstream/ riufc/7696/1/2013_dis_ffboliveira.pdf.> Acesso em 14 abr. 2015.

Oliveira F., Akisue G. \& Akisue M.K. 1998. Farmacognosia. Atheneu, São Paulo, p.59-65.

Page-McCaw A., Ewald A.J. \& Werb Z. 2007. Matrix metalloproteinases and the regulation of tissue remodeling: a review. Nat. Rev. Mol. Cell Biol. 8(3):221-233.

Parks W.C., Wilson C.L. \& Lopez-Boado Y.S. 2004. Matrix metalloproteinases as modulators of inflammation and innate immunity. Nature Reviews, Immunology. 4(8):617-629.

Paula-Junior W., Rocha F.H., Donatti L., Fadel-Picheth C.M.T. \& Weffort-Santos A.M. 2006. Leishmanicidal, antibacterial, and antioxidant activities of Caryocar brasiliense Cambess leaves hydroethanolic extract. Revta Bras. Farmacogn. 16:625-630.

Pereira F.E.L. 2011. Etiopatogênese geral das lesões, p.49. In: Brasileiro Filho G. (Ed.), Bogliolo Patologia. 8 ${ }^{\underline{a}}$ ed. Guanabara Koogan, Rio de Janeiro. $1524 \mathrm{p}$.

Pontes J.C.D.V., Gomes Júnior J.F., Silva G.V.R., Benfatti R.A., Dias A.E.M.A.S.J., Duarte J.J., Gardenal N., Maçanori Odashiro M. \& Santos C.H.M. 2010. Estudo anatomopatológico da miocardiopatia induzida pela doxorrubicina em ratos. Acta Cir. Bras. 25(2):137-143.

Potácová A., Adamcová M., Sterba M., Popelová O., Simůnek T., Mazurová Y., Guncová I. \& Gersl V. 2007. A pilot study of matrix metalloproteinases on the model of daunorubicin-induced cardiomyopathy in rabbits. Acta Medica, Hradec Kralove, 50(2):109-111.

Raj S., Franco V.I. \& Lipshultz S.E. 2014. Anthracycline-induced cardiotoxicity: a review of pathophysiology, diagnosis, and treatment. Curr. Treat Options Cardio. Med. 16(315):1-14. doi: 10.1007/s11936-014-0315-4.

Reinhardt D., Sigusch H.H., Henbe J., Tyagi S.C., Korfer R. \& Figulla H.R. 2002. Cardiac remodelling in the end stage heart failure: upregulation of matrix metalloproteinase (MMP) irrespective of underlying disease, and evidence for a direct inhibitory effect of AEC inhibitors on MMP. Heart 88(5):525-530.

Roesler R., Malta L.G., Carrasco L.C., Holanda R.B., Sousa C.A.S. \& Pastore G.M. 2007. Atividade antioxidante de frutas do cerrado. Ciência e Tecnologia de Alimentos 27(1):53-60.

Santos A.C.S., Mesquita E.T., Menezes M.E.F.C., Costa M.P. \& Santos M.C.S. 2009. Cardioncologia: anormalidades eletrocardiográficas em pacientes com cardiomiopatia pós-uso de doxorrubicina. Revta SOVERJ 22(5): 281-288.

Sousa M.G. 2007. Função cardíaca de cães submetidos ao transplante autólogo de células-tronco hematopoiéticas em dois modelos experimentais de cardiomiopatia. Tese de Doutorado, Universidade Estadual Paulista, Campus de Jaboticabal. Disponível em <http://repositorio.unesp. br/handle/11449/101244>. Acesso em 14 jan. 2014.

Steinherz L.J., Steinherz P.G., Tan C.T.C., Heller G. \& Murphy M.L. 1991. Cardiac toxicity 4 to 20 years after completing anthracycline therapy. J. Am. Med. Assoc. 266:1672-1677.

Vanhoutte D., Schellings M., Pinto Y. \& Heymans S. 2006. Relevance of matrix metalloproteinases and their inhibitors after myocardial infarction: A temporal and spatial window. Cardiovasc. Res. 69:604-613.

Visse R. \& Nagase H. 2003. Matrix metalloproteinases and tissue inhibitors of metalloproteinases: structure, function, and biochemistry: a review. Cir. Res. 92(8):827-839.

Walker J.R., Sharma A., Lytwyn M., Bohonis S., Thliveris J., Singal P.K. \& Jassal D.S. 2011. The cardioprotective role of probucol against anthracycline and trastuzumab-mediated cardiotoxicity. J. Am. Soc. Echocardiogr. 24(6):699-705. doi: 10.1016/j.echo.2011.01.018

Woessner J.F. \& Nagase H. 2000. Matrix metalloproteinases and TIMPs. Oxford University Press, p.130-135.

Xin Y.F., Wan L.L., Peng J.L. \& Guo C. 2011. Alleviation of the acute doxorubicin-induced cardiotoxicity by Lycium barbarum polysaccharides through the suppression of oxidative stress. Food Chem. Toxicol. 49(1):259-264. doi: 10.1016/j.fct.2010.10.028 